\title{
VARIABILIDADE DE Colletotrichum lindemuthianum EM FEIJOEIRO COMUM NO OESTE DO ESTADO DO PARANÁ
}

\author{
VARIABILITY OF Colletotrichum lindemuthianum IN COMMON BEAN IN \\ WESTERN PARANÁ
}

\author{
Lucimar Pereira BONETT ${ }^{1}$ \\ Ivânia SCHEWE ${ }^{2}$ \\ Luciano Ivano da SILVA ${ }^{2}$
}

\begin{abstract}
RESUMO
A grande variabilidade patogênica do fungo Colletotrichum lindemuthianum e a ampla distribuição geográfica em regiões produtoras de feijão no Brasil vêm causando sérios problemas a produtores e melhoristas. Assim, o objetivo deste trabalho foi realizar um levantamento de raças de Colletotrichum lindemuthianum provenientes de cultivos de feijoeiro comum no Oeste do Estado do Paraná, região de destaque na produção brasileira. Após coleta das vagens com antracnose e a desinfecção superficial, com hipoclorito de sódio, fragmentos das lesões foram transferidas para meio BDA e estreptomicina, seguidas de incubação por oito dias a $28^{\circ} \mathrm{C}$. Para a seleção de isolados o micélio do fungo foi repicado duas ou três vezes em placa de Petri contendo o mesmo meio. Após a incubação obteve-se uma suspensão de esporos, pelo método de diluições, a qual foi ajustada para a concentração de $1,2 \times 10^{6}$ esporos $\mathrm{mL}^{-1}$. Aplicou-se a suspensão na primeira folha trifoliolada das doze cultivares diferenciadoras. Após 10 dias avaliaram-se os sintomas, adotando-se a escala de notas de um a nove. Dentre os 61 isolados avaliados, identificaram-se as raças 52, 65, 81, 83, 321 e 337 . As raças 52,83 e 337 foram observadas pela primeira vez em cultivos de feijoeiro comum no Oeste do Estado do Paraná, o que comprova o aumento da variabilidade do patógeno na região e a necessidade de monitoramento periódico.
\end{abstract}

Palavras-chave: Antracnose; cultivares diferenciadoras; raças.

\begin{abstract}
The great pathogen variability of the fungus Colletotrichum lindemuthianum and its widespread distribution across several common bean regions in Brazil, particularly in the southern and southeastern regions, is causing serious problems for producers as well as breeders. The purpose of this paper was the identification of Colletotrichum lindemuthianum races in common bean fields in the western part of Paraná state, one of the leaders in the Brazilian production. Anthracnose-infected pods were collected and the surface disinfected with sodium hypochlorite. Lesion fragments were transferred to PDA medium containing streptomycin and incubated for eight days at $28{ }^{\circ} \mathrm{C}$. For selection of the isolates the mycelium of the fungus were seeded two or three times on Petri dishes with the same medium. After incubation a spore solution was obtained by the dilution method, adjusted to a concentration of $1.2 \times 10^{6}$ spores $\mathrm{mL}^{-1}$. The suspension was applied on the first trifoliote leaf of the 12 differentiating cultivars. The symptoms were evaluated after 10 days, on a 1 to 9 scale. Among the 61 evaluated isolates, the races $52,65,81,83,321$, and 337 were identified. The races 52,83 and 337 were observed for the first time in common bean fields in western Paraná that demonstrates increase in the variability of the pathogen in the region and the need of a periodic monitoring.
\end{abstract}

Key-words: Anthracnose; differentiating cultivars; races.

\footnotetext{
${ }^{1}$ Engenheira Agrônoma, Doutora em Agronomia, Professora do Curso de Ciências Biológicas da Universidade Paranaense - Campus Toledo, Avenida Parigot de Souza, 3636, Jardim Prada, Toledo-PR, CEP: 85903-170. E-mail: lucimar@unipar.br. Autor para correspondência.

${ }^{2}$ Acadêmicos do Programa de Iniciação Científica, Universidade Paranaense - Campus Toledo, Avenida Parigot de Souza 3636, Jardim Prada, Toledo-PR, CEP: 85903-170.
} 


\section{INTRODUÇÃO}

O feijoeiro comum (Phaseolus vulgaris L.) é a espécie mais cultivada do gênero Phaseolus, contribuindo com $95 \%$ da produção mundial de feijões. Esta é cultivada em aproximadamente 100 países, destacando-se a Índia, o Brasil, a China, os Estados Unidos e o México. Dentre eles, o Brasil é o maior produtor. O Estado do Paraná é o maior produtor brasileiro contribuindo com cerca de $22 \%$ da produção nacional (MODA-CIRINO, 2007).

Os programas de melhoramento do feijoeiro no Brasil têm concentrado esforços, principalmente, no aumento da produção de grãos e na resistência a doenças, pois o baixo rendimento da cultura, em torno de $700 \mathrm{~kg} \mathrm{ha}^{-1}$, e o elevado número de doenças podem ser o resultado, entre outros motivos, do pequeno uso de sementes fiscalizadas e do manejo inadequado da cultura (VIEIRA et al., 2005).

A transmissibilidade eficiente pelas sementes e as perdas econômicas proporcionadas qualificam a antracnose, cujo agente causal é o fungo Colletotrichum lindemuthianum (Sacc. et Magn.) Scrib., como um das doenças mais importante do feijoeiro (RAVA et al., 1994). O fungo $C$. lindemuthianum possui uma alta variabilidade patogênica e se distribui em diversas regiões produtoras de feijão no Brasil, especialmente nas regiões Sul e Sudeste e em áreas Serranas (VIEIRA et al., 2005).

A padronização de doze cultivares diferenciadoras e o uso do sistema binário de HABGOOD (1970), para classificar as raças do patógeno tem facilitado a comprovação dos resultados e o intercâmbio de informações sobre as raças de C. lindemuthianum (ISHIKAWA, 2006).

De acordo com RODRIGUEZ-GUERRA et al. (2003) mais de cem raças de $C$. lindemuthianum já foram identificados em todo o mundo, e segundo ALZATE-MARIN e SARTORATO (2004), no Brasil existem mais de cinqüenta raças, sendo $65,73,81$ e 87 as mais freqüentes nesses últimos anos no país.

A resistência genética apresenta efeito estabilizador sobre as cultivares, evitando-lhes uma oscilação de rendimento de plantio para plantio, em função do maior ou menor ataque de patógenos (VIEIRA et al., 2005) assim, faz-se necessário o monitoramento da variabilidade da população desse fungo, pois novas raças podem comprometer o uso de cultivares de feijoeiros tradicionais ou recentemente lançados no mercado (TALAMINI et al. 2004).

Considerando os aspectos levantados o objetivo deste trabalho foi fazer um levantamento da variabilidade patogênica entre os isolados de Colletotrichum lindemuthianum provenientes do Oeste do Estado do Paraná.

\section{Obtenção dos isolados}

MATERIAL E MÉTODOS

Os 61 isolados utilizados neste trabalho foram obtidos a partir de vagens com sintomas de antracnose, provenientes de cultivos de feijoeiro implantados nos municípios da região oeste do Estado do Paraná durante o ano agrícola de 2004/ 2005. Fragmentos das lesões contidas nas vagens foram transferidos para o meio de cultura batatadextrose-ágar (BDA) que a partir da produção dessas colônias, foram isoladas colônias monospóricas. As coletas foram realizadas em 05 municípios dentre os 51 que constituem a região oeste do Estado do Paraná. No município de Marechal Cândido Rondon foram obtidos três isolados, dezoito em Terra Roxa, sete em Nova Santa Rosa, quatorze em Cascavel e vinte isolados no município de Toledo.

\section{Isolamento e teste de patogenicidade}

Após a coleta, as vagens com antracnose foram submetidas à desinfecção superficial por meio de imersão, durante um minuto, em solução de hipoclorito de sódio comercial (contendo $5 \%$ de cloro ativo), diluído na proporção de uma parte do produto para três partes de água destilada esterilizada. Seguiu-se com lavagens por duas vezes em água destilada esterilizada, sendo as vagens secas com papel toalha para retirar 0 excesso de umidade. Fragmentos das lesões características de antracnose foram transferidos para meio batata-dextrose-ágar (BDA), suplementado com $150 \mathrm{mg} \mathrm{L}^{-1}$ do antibiótico estreptomicina e, em seguida foi realizada a incubação por um período de cinco dias a $28^{\circ} \mathrm{C}$, em estufa tipo BOD. Para a obtenção das culturas monospóricas cada isolado foi repicado de duas a três vezes para uma nova placa de Petri contendo meio de cultura BDA. Após a colonização total das placas, estas foram armazenadas em geladeira.

Com o término do período de incubação, efetuou-se a retirada do conteúdo das placas de petri com os esporos, transferindo-os para um "becker" com água destilada esterilizada, originando, dessa forma, uma suspensão de esporos. Tal suspensão foi filtrada através de uma camada de gaze dupla, de forma a obter-se uma suspensão com os esporos. Para cada isolado do patógeno foram efetuadas de quatro a cinco contagens em câmara de Neubauer. Utilizando-se o método de diluições, a concentração de esporos foi ajustada para $1,2 \times 10^{6}$ esporos $\mathrm{mL}^{-1}$, de água destilada esterilizada, conforme concentração utilizada por RAVA et al. (1993).

Para o teste de patogenicidade, foram semeadas doze sementes de cada cultivar e da testemunha suscetível. As sementes destas cultivares foram distribuídas em bandejas de isopor de 128 células, contendo substrato comercial. Após cinco dias a temperatura de $25^{\circ} \mathrm{C}$, em casa de vegetação, as plântulas foram submetidas à inoculação com pincel molhado no inóculo e mantidas em ambiente de $22 \pm 2{ }^{\circ} \mathrm{C}$ e umidade relativa mínima de $90 \%$, por $48 \mathrm{~h}$ e, em seguida, mantidas nas mesmas condições, exceto a umidade. A avaliação dos sintomas deu-se após ter transcorrido 10 dias da inoculação, adotando-se uma escala de notas de um (resistentes e sem 
sintomas) a nove (suscetíveis e mortas), descrita por SCHOONHOVEN e PASTOR-CORRALES (1987) sendo que plantas com notas um, dois e três foram consideradas resistentes e plantas com notas igual ou superior a quatro foram consideradas suscetíveis. Se a média das notas das plântulas de uma mesma cultivar apresentavam média maior ou igual a 3,6, a cultivar foi considerada suscetível.

\section{RESULTADOS E DISCUSSÃO}

Seis raças de Colletotrichum lindemuthianum foram identificadas entre os sessenta e um isolados coletados na região Oeste do Estado do Paraná, sendo elas, raças 52, 65, 81,
83, 321 e 337 (Tabela 1). Dentre esses isolados, vinte e dois pertencem a raça 52 , com $36,06 \%$ do total de isolados, onze a 65 , com $18,03 \%$, onze a 321 , com $18,03 \%$, oito a 83 , representando $13,11 \%$ e, com menor freqüência, as raças 81 e 337, com cinco $(8,20 \%)$ e quatro $(6,56 \%)$ isolados, respectivamente. No Estado do Paraná, RAVA et al. (1994) identificaram as raças $55,64,65,81,89$, 95,102 e 453 e CARNEIRO (1999) em setenta isolados coletados, identificou as raças $65,69,73$, 81, 87, 89 e 342. Já THOMAZELLA (2000), avaliou 18 isolados, sendo as raças 89,81 e 65 as de maior freqüência. No presente estudos, destas raças, apenas as 65 e 81 foram identificadas.

TABELA 1 - Reação das cultivares diferenciadoras de feijoeiro comum aos isolados do agente causal da antracnose (Colletotrichum lindemuthianum) e identificação de raças.

\begin{tabular}{ccccccccccccccccc}
\hline & \multicolumn{1}{c}{ Raças } & $2^{0}$ & $2^{1}$ & $2^{2}$ & $2^{3}$ & $2^{4}$ & $2^{5}$ & $2^{6}$ & $2^{\prime}$ & $2^{8}$ & $2^{9}$ & $2^{10}$ & $2^{11}$ & Número \\
& 1 & 2 & 4 & 8 & 16 & 32 & 64 & 128 & 256 & 512 & 1024 & 2048 & de \\
& 1 & - & - & + & - & + & + & - & - & - & - & - & - & 22 \\
\hline 52 & - & - & - & - & - & - & + & - & - & - & - & - & 11 \\
65 & + & - & - & - & + & - & + & - & - & - & - & - & 05 \\
81 & + & - & - & - & - & - & + & - & - & - & - & - & 08 \\
83 & + & + & - & - & - & - & - & - & 11 \\
321 & + & - & - & - & + & - & + & - & + & - & - & - & - \\
337 & + & - & - & - & - & - & - & - & + & - & - & - & 04 \\
\hline
\end{tabular}

"Cultivares diferenciadoras (valor da cultivar): Michelite (1), Michigan Dark Red Kidney (2), Perry Morrow (4), Cornell 49-242 (8), Widusa (16), Kaboon (32), México 222 (64), PI 207262 (128), TO (256), TU (512), AB 136

(1024) e G2333 (2048); + = reação de compatibilidade; - =: reação de incompatibilidade

Em outras regiões geográficas do Brasil como a região Sudeste representada por São Paulo e Minas Gerais; Sul do Paraná, Santa Catarina e Rio Grande do Sul; Centro-Oeste pelo Distrito Federal, Goiás e Mato Grosso do Sul e região Nordeste pela Bahia, SILVA (2004) identificou 19 raças, dentre elas a 81,83 e 337 , constatando que as raças 65 , seguida das raças 81 e 73 foram as mais freqüentes.

Nas regiões do Alto Parnaíba, sul de Minas, Zona da Mata e Triângulo Mineiro no estado de Minas Gerais, Cristalina no estado de Goiás, Pindamonhangaba no Estado de São Paulo e Lapa, no Estado do Paraná, TALAMINI et al. (2004) confirmaram a presença das raças 65 e 81 . SARTORATO (2002) no estado do Paraná identificou 19 raças, dentre elas a 65,81 e a 321 , relatada pela primeira vez no Brasil. Em regiões produtoras de feiião do Rio Grande do Sul, SOMAVILLA e PRESTES (1999), relataram ocorrência de 11 raças dentre as quais estava inclusa a 83 , e constataram que as raças 65 e 81 foram as mais freqüentes. O presente trabalho confirmou a presença das raças 65,81 e 321 no estado do Paraná corroborando com os resultados encontrados pelos autores acima citados. Identificou-se, também, a presença das raças 83 e 337 relatadas em outras regiões, e pela primeira vez no estado do Paraná. Detectou-se, ainda, a presença da raça 52 sem relato no País até o momento (Tabela 1).
Os resultados obtidos com o presente trabalho confirmam os resultados já encontrados no Brasil e estado no Paraná sobre a variabilidade do fungo $C$. lindemuthianum, quanto à sua variabilidade patogênica e que as raças 65 e 81 continuam em destaque como mais freqüentes e de ampla distribuição no Brasil, que de acordo com REY et al. (2005) e TALAMINI et al. (2004) é favorecida, principalmente, pela transmissão por meio de sementes e pelo livre comércio de grãos utilizados como sementes entre os estados e segundo, SILVA (2004), devido principalmente ao uso de cultivares suscetível a estas raças, como Pérola e Carioca, nos estados produtores.

\section{CONCLUSÕES}

Os resultados obtidos com este trabalho permitiram confirmar a continuidade das raças 65 , 81 e 321 , identificar as raças 83 e 337, já relatadas em outras regiões, porém constatada pela primeira vez em cultivos de feijoeiro comum no oeste do estado do Paraná e, detectar a presença da raça 52 sem relato no Brasil até o momento, comprovando assim, a variabilidade do patógeno.

A presença das raças 52, 83 e 337 comprova a necessidade da verificação periódica da variabilidade patogênica do fungo Colletotrichum lindemuthianum. 


\section{REFERÊNCIAS}

1. ALZATE-MARIN, A.L.; SARTORATO, A. Analysis of the pathogenic variability of Colletotrichum lindemuthianum in Brazil. Annual Report of Bean Improvement Cooperative, v.47, p.241-242, 2004.

2. CARNEIRO, S.M. de T.P.G. Physiological races Colletotrichum lindemuthianum in Paraná State-Brazil. Summa Phytopathologica, v.25, n.3, p.275-278, 1999.

3. HABGOOD, H. Designation of physiological races of plant pathogens. Nature, v. 227, n. 5264, p. 1268-1269, 1970.

4. ISHIKAWA, F.H. Variabilidade genética de isolados da raça 65 de Colletotrichum lindemuthianum por meio de marcadores RAPD e Grupos de anastomoses. Lavras, 2006. 52 f. Dissertação (Mestrado em Genética e melhoramento de Plantas) - Curso de Pós Graduação em Agronomia, Universidade Federal de Lavras.

5. MODA-CIRINO, V. Desafios ao controle de pragas na cultura do feijoeiro: desafios na Região Sul. Campinas: Instituto Agronômico, 2007. 250 p. (IAC. Documentos, 79).

6. RAVA, C.A.; MOLINA, J.; KAUFFMANN, M. BRIONES, I. Determinación de razas fisiológicas de Colletotrichum lindemuthianumun en Nicarágua. Fitopatologia Brasileira, v. 18, n. 3, p. 388-391, 1993.

7. RAVA, A.; PURCHIO, A.F.; SARTORATO, A. Caracterização de patótipos de Colletotrichum lindemuthianum que ocorrem em algumas regiões produtoras de feijoeiro comum. Fitopatologia Brasileira, v. 19, n. 2, p. 167-172, 1994.

8. REY, M. dos S.; BALARDIN, R.; PIEROBOM, C.R. Reação de cultivares de feijoeiro comum (Phaseolus vulgaris L.) a patótipos de Colletotrichum lindemuthianum. Revista Brasileira de Agrociência, v.11, n.1, p. 113-116, 2005.

9. RODRIGUEZ-GUERRA, R.; RAMÍREZ-RUEDA, M.T.; MARTINEZ DE LA VEJA.; SIMPSON, J. Varitaion in genotype, pathotype and anãstomosis groups of Colletotrichum lindemuthianum isolates from México. Plant Pathology, v. 52, p. 228-235, 2003.

10. SARTORATO, A. Determinação da variabilidade patogênica do fungo Colletotrichum lindemuthianum (Sacc.) Scrib. In: CONGRESSO NACIONAL DE PESQUISA DE FEIJÃO, 7., 2002, Viçosa. Resumos. Viçosa: UFV, 2002. p.114-116.

11. SCHOONHOVEN, A. VAN; PASTOR-CORRALES, M.A.; Sistema estándar para la evaluación del germoplasma del frijol. Cali, Colômbia: CIAT, 1987. 54 p.

12. SILVA, K.J.D. Distribuição e caracterização de isolados de Colletotrichum lindemuthianum no Brasil. Lavras, 2004. 86 f. Dissertação (Mestrado em Genética e melhoramento de Plantas) - Curso de Pós Graduação em Agronomia, Universidade Federal de Lavras.

13. SOMAVILLA, L.; PRESTES, A.M. Identificação de patótipos de Colletotrichum lindemuthianum de algumas regiões produtoras de feijão do Rio Grande do Sul. Fitopatologia Brasileira, v. 24, n. 3, p. 416-421, 1999.

14. TALAMINI, V.; SOUZA, E.A.; POZZA, E.A.; CARRIJO, F.R.F.; ISHIKAWA, F.H.; SILVA, K.J.D.; OLIVEIRA, F.A. de. Identificação de raças patogênicas de Colletotrichum lindemuthianum a partir de isolados provenientes de regiões produtoras de feijoeiro comum. Summa Phytopathologica, v. 30, n. 3, p. 371-375, 2004.

15. THOMAZELLA, C.; GONÇALVES-VIDIGAL, M.C.; VIDA, J.B.; VIDIGAL FILHO, P.S.; RIMOLDI, F. Identification of Colletotrichum lindemuthianum races in Phaseolus vulgaris L. In: Annual Report of the Bean Improvement Cooperative, v. 43, p.82-83, 2000.

16. VIEIRA, C.; BORÉM. A.; RAMALHO, M.A.P.; CARNEIRO, J.E. de S. Melhoramento de Feijão In: BORÉM, A. (Ed.). Melhoramento de espécies cultivadas. Viçosa: Universidade Federal de Viçosa, 2005. p 301-391.

Recebido em 18/07/2007

Aceito em 12/02/2008 